This item was submitted to Loughborough's Research Repository by the author.

Items in Figshare are protected by copyright, with all rights reserved, unless otherwise indicated.

\title{
Enhanced condition monitoring of the machining process using wavelet packet transform
}

\section{PLEASE CITE THE PUBLISHED VERSION}

https://doi.org/10.1201/9781351174664

\section{PUBLISHER}

(C) Taylor and Francis

\section{VERSION}

VoR (Version of Record)

\section{PUBLISHER STATEMENT}

This work is made available according to the conditions of the Creative Commons Attribution-NonCommercialNoDerivatives 4.0 International (CC BY-NC-ND 4.0) licence. Full details of this licence are available at: https://creativecommons.org/licenses/by-nc-nd/4.0/

\section{LICENCE}

CC BY-NC-ND 4.0

\section{REPOSITORY RECORD}

Mao, Lei, Lisa M. Jackson, Paul A. Goodall, and Andrew A. West. 2019. "Enhanced Condition Monitoring of the Machining Process Using Wavelet Packet Transform". figshare. https://hdl.handle.net/2134/37276. 


\title{
Enhanced condition monitoring of the machining process using wavelet packet transform
}

\author{
L. Mao \& L.M. Jackson \\ Department of Aeronautical and Automotive Engineering, Loughborough University, UK \\ P. Goodall \& A. West \\ Department of Mechanical, Electrical and Manufacturing Engineering, Loughborough University, UK
}

\begin{abstract}
Tool wear in machining processes can have a detrimental impact upon the surface finish of a machined part, increase the energy consumption during manufacture and potentially, if the tool fails completely, damage incurred may require the part to be scrapped. Monitoring of the tools condition can therefore lead to preventative steps being taken to avoid excessively worn tools being used during machining, which could cause a part becoming damaged. Several studies have been devoted to condition monitoring of the machining process, including the evaluation of cutting tool condition. However, these methods are either impractical for a production environment due to lengthy monitoring time, or require knowledge of cutting parameters (e.g. spindle speed, feed rate, material, tool) which can be difficult to obtain. In this study, we aim to investigate if tool wear can be directly identified using features extracted from the electrical power signal of the entire Computer Numerical Control (CNC) machine (three phase voltage and current) captured at $50 \mathrm{KHz}$, for different cutting parameters. Wavelet packet transform is applied to extract the feature from the raw measurement under different conditions. By analyzing the energy and entropy of reconstructed signals at different frequency sub-bands, the tool wear level can be evaluated. Results demonstrate that with the selected features, the effects due to cutting parameter variation and tool wear level change can be discriminated with good quality, which paves the way for using this technique to monitor the machining process in practical applications.
\end{abstract}

\section{INTRODUCTION}

Tool wear and subsequent failure of tools during the manufacturing process will have a significant impact on the economics of machining, and about $25 \%$ of machine down time can be attributed to the direct results of tool wear failure (Altintas \& Yellowley 1989). Moreover, the development of tool wear will give rise to inconsistencies in surface finishes and geometric tolerances, affecting the quality of manufactured products. Therefore, a series of studies have been devoted to monitoring systems detecting underperforming tooling and improving machining efficiency and productivity.

The monitoring techniques for tool wear can be divided into two categories, direct and indirect methods (Bhattacharyya \& Sengupta 2009, Teti et al. 2010). With direct methods, tool wear is evaluated by analyzing the cutter itself, such as measuring the surface roughness and flank wear, etc. On the other hand, indirect methods apply either model-based or data-driven techniques to the measurements like cutting force, tool vibration and output power for evaluating tool wear conditions. It should be noted that due to the restrictions of direct methods such as stopping requirements during production, indirect methods are more suitable for industrial applications (Zhu et al. 2009).

With indirect methods, different measurements can be collected and analyzed to evaluate the tool condition, including acoustic emission (Prickett \& Johns 1999, Karimi et al. 2013, Hass et al 2013), cutting force (Dimla \& Lister 2000, Li et al. 2006, Deng et al. 2013, Lee et al. 2006), vibration (Yesilyurt \& Ozturk 2007, Zhang \& Chen 2007, Lamraoui et al. 2014), temperature (Byrne 1987, Davoodi \& Hosseinzadeh 2012), spindle power/current (He et al. 2017, Li et al. 2000, Simoneau \& Meehan 2013), etc. However, several of these methods often require expensive sensing equipment (Nouri et al. 2015) and can be difficult to install due to the need for close proximity to the cutting tool and workpiece, meaning they can be impractical for large production environments. Additionally, the classification of tool wear from the collected data is challenging due to the high sensitivity of data to the cutting parameters (i.e. spindle speed, feed rate, depth and width of cut, material, tool type). Thresholding of time domain data has been used as a method of classifying tool wear (Shao et al. 
2004), however, this requires large amounts of calibration and training data which is time consuming to collect and reduces the robustness of the system to a limited set of cutting conditions. Several studies of investigated frequency and time-frequency domain analysis to reduce the sensitivity to classification to cutting parameters (Kuljanic et al. 2009, Liao et al. 2007, Huang et al. 2010, Lauro et al. 2004], however, most of these methods require specialist monitoring equipment which pose the challenges described above.

Within this research we investigate the potential of a low cost, non-invasive sensing approach which is also cutting parameter agnostic to the problem of tool condition monitoring, which has so far not been identified within existing literature. The investigated solution uses current and voltage sensors across electrical three phase input to the machine to monitor the overall machine power consumption, whilst classification of the signal is conducted though time-frequency analysis using wavelet packet transform.

In Section 2 the diagnostic approach using the wavelet analysis is described. Section 3 details the experimental methodology and results, and Section 4 concludes the findings and highlights limitations and future work.

\section{DIAGNOSTIC APPROACH}

Although several studies have been performed for condition monitoring of the milling process using wavelet transform [Choi et al. 2004, Li et al. 2008, Zhong et al. 2010], these have mainly used vibration or cutting force measurements in the analysis instead of electrical power consumed by the machine. Moreover, the effectiveness of wavelet transform in discriminating tool wear level operated at varying cutting parameters still requires further investigation.

In this study, wavelet packet transform (WPT) is selected to evaluate the tool wear level. The reason of using WPT is that compared to wavelet transform, which only filters the signal to get the low-pass results (approximation), WPT can filter the signal to obtain both low-pass and high-pass (detailed) results (depicted in Figure 1). Therefore, more information can be extracted from the original signals using WPT [Torrence \& Compo, 1995]. The extracted wavelet coefficients $C_{j, k}$ can be expressed using Eq. (1).

$$
C_{j, k}=\int f(t) \psi_{j, k}(t) d t
$$

where $f(t)$ is the original signal, $\psi_{j, k}$ is the wavelet function, $j$ and $k$ are the scale and shift parameters, this can be expressed in Eq. (2).

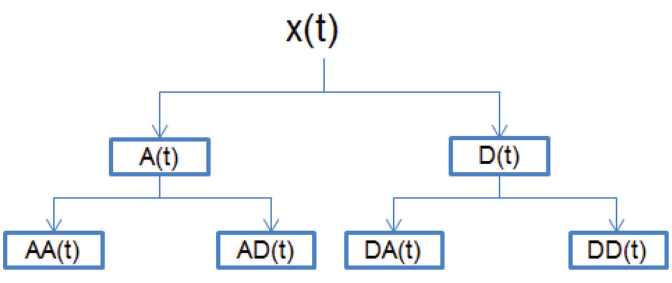

Figure 1. Two-level wavelet packet transform, where A and $\mathrm{D}$ are the approximation and detail by filtering the signal at the previous level.

$\psi_{j, k}(t)=\frac{1}{\sqrt{j}} \psi\left(\frac{t-k}{j}\right)$

It can be seen from Figure 1 that the application of WPT provides a sub-band filtering of the original signal into progressively finer equal-width intervals with the extracted packets of wavelet coefficients, i.e. the $i^{\text {th }}$ packet of wavelet coefficients at $j^{\text {th }}$ level represent the information of original signal within the frequency sub-band of $\left[i F_{s} / 2^{j+1},(i+1) F_{s} / 2^{j+1}\right]$, where $F_{s}$ is the sampling frequency.

With wavelet coefficients, the time-history of signals at different frequency sub-bands can be reconstructed using Eq. (3).

$$
f_{j}(t)=C \sum_{k} C_{j, k} \psi_{j, k}(t)
$$

where $\mathrm{C}$ is a constant independent of signals.

With these constructed signals, energy and entropy are calculated from each signal using Eqs. (4) and (5).

$$
\begin{aligned}
& E_{S}=\int|f(t) f(t)| d t \\
& H_{s}=-\sum_{i=1}^{N} p\left(x_{i}\right) \log _{10} p\left(x_{i}\right)
\end{aligned}
$$

where $E_{s}$ and $H_{s}$ are the energy and entropy of the signal, $p\left(x_{i}\right)$ in Eq. (5) is a probability of the signal with value of $x_{i}$.

The energy of reconstructed signals represents the amount of information within different frequency sub-bands, while entropy of reconstructed signals can indicate the signal disorganization at the frequency sub-bands. It is expected that these two features would be sensitive to the change of cutting parameters and cutting tool wear level, thus can be used for the discrimination of cutting tool levels. This will be further investigated in the following section.

It can be seen that with the use of WPT, the original signals can be decomposed and reconstructed 
at different frequency ranges, from which the frequency information can be related to the signals in the time domain, and better used for the feature extraction and fault diagnosis.

\section{PERFORMANCE OF DIAGNOSTIC APPROACH}

\subsection{Experiments}

In the study, HSS-Co8 is selected as the end milling tool due to its ease of wear measurement, which is a high speed steel containing $8 \%$ cobalt with 4 flutes. Two end milling tools with different diameters are selected herein for the analysis. Table 1 lists the characteristics of these end milling tools, where LOC refers to the tool's length of cut.

In the experiments, each end mill was assigned a work piece of dimension $150 \mathrm{~mm} \times 120 \mathrm{~mm} \times 30 \mathrm{~mm}$, and the plate material was selected as commercial aluminum grade 6082 T651, which is a common alloy used in manufacturing.

Cutting parameters used in the tests were selected according to the manufacture's recommendation, which are listed in Table 2.

For the duration of each cutting session the energy monitoring device was connected to the system, which collected the current and voltage measurements at a sampling frequency of $50 \mathrm{kHz}$. During each session, the tools were used to per-

Table 1. Characteristics of end milling tools.

\begin{tabular}{lllll}
\hline $\begin{array}{l}\text { Mill Dia. } \\
(\mathrm{mm})\end{array}$ & $\begin{array}{l}\text { Shank Dia. } \\
(\mathrm{mm})\end{array}$ & $\begin{array}{l}\text { LOC } \\
(\mathrm{mm})\end{array}$ & $\begin{array}{l}\text { Overall } \\
\text { length } \\
(\mathrm{mm})\end{array}$ & $\begin{array}{l}\text { No. } \\
\text { teeth/ } \\
\text { flutes }\end{array}$ \\
\hline 8.0 & 10 & 19 & 69 & 4 \\
10.0 & 10 & 22 & 72 & 4 \\
\hline
\end{tabular}

Table 2. Cutting parameters and corresponding wear measurements.

\begin{tabular}{lcclll}
\hline $\begin{array}{l}\text { Dia. } \\
(\mathrm{mm})\end{array}$ & $\begin{array}{l}\text { Cut } \\
\text { no. }\end{array}$ & $\begin{array}{l}\text { Time } \\
(\mathrm{min})\end{array}$ & $\begin{array}{l}\text { Spindle } \\
\text { speed } \\
(\mathrm{RPM})\end{array}$ & $\begin{array}{l}\text { Feed } \\
\text { rate } \\
(\mathrm{m} / \mathrm{min})\end{array}$ & $\begin{array}{l}\text { Localized } \\
\text { tool wear } \\
(\mathrm{mm})\end{array}$ \\
\hline 8 & 1 & 0 & 4000 & 580 & 0 \\
8 & 2 & 40 & 4000 & 580 & 0.182 \\
8 & 3 & 60 & 4000 & 580 & 0.279 \\
8 & 4 & 80 & 4000 & 580 & 0.327 \\
8 & 5 & 100 & 4000 & 580 & 0.493 \\
10 & 1 & 0 & 3100 & 600 & 0 \\
10 & 2 & 40 & 3100 & 600 & 0.185 \\
10 & 3 & 80 & 3100 & 600 & 0.434 \\
10 & 4 & 100 & 3100 & 600 & 0.582 \\
\hline
\end{tabular}

form climb milling on the work pieces. The number of passes, cut depth and cutting radius are selected as 10 , half of the cutter diameter, respectively.

It should be mentioned that after each cutting session, the tools were used to machine the carbon steel to induce wear ( $40 \mathrm{~min}$ initially, subsequently $20 \mathrm{~min}$ ), and this process was repeated until $100 \mathrm{~min}$, where full tool wear was observed. Table 2 lists the cutting parameters used for different cuts and corresponding wear measurements.

\subsection{Discrimination of different cutting tools with different wear level}

In this section, the current and voltage from two end milling tools with $8 \mathrm{~mm}$ and $10 \mathrm{~mm}$ cutting diameters are collected at $0 \mathrm{~min}$ and $100 \mathrm{~min}$, which represents the intact and fully worn tools. The reason of selecting these measurements is that the collection process will not interrupt the machining process, and the installation of sensors will not add complexity of monitoring systems, thus the results can be better applied in the practical machining process. With current and voltage measurements, the instantaneous power can be calculated using the following equation.

$$
P_{\text {ins }}(t)=v(t) i(t)
$$

where $v(t)$ and $i(t)$ are the collected voltage and current measurements at time $\mathrm{t}$.

Figure 2 depicts the instantaneous powers for $8 \mathrm{~mm}$ and $10 \mathrm{~mm}$ tools at intact and fully worn conditions. It should be mentioned that only power from single pass cutting is illustrated herein, as the powers of 10 passes have a similar trend. In the current study, only the power from a single pass is analyzed. Table 3 lists the average and maximum instantaneous power at each condition. It can be seen from the table that the instantaneous power will be increased with cutting tool wear.

From the instantaneous powers shown in Figure 2, the cutting tools with different diameters and cutting parameters, and the same tool with different wear levels cannot be discriminated easily in the time-domain, as the signals from different conditions have a similar shape, thus the four different conditions cannot be discriminated using only the power amplitude variation.

As described in section 2, WPT is applied to the instantaneous power to extract wavelet coefficients and reconstruct signals at different frequency subbands. In the current study the WPT is used to decompose the original signal over 8 levels. This decomposition level is selected by considering both the range of frequency sub-band and computational time. In the current study the Shannon wavelet 


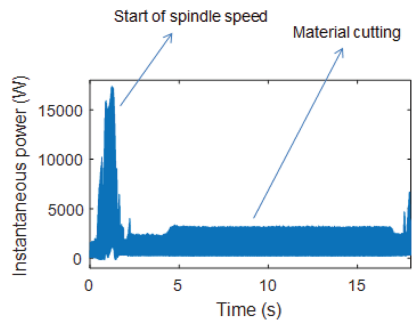

(a)Instantaneous power of $8 \mathrm{~mm}$ cutter at $0 \mathrm{~min}$

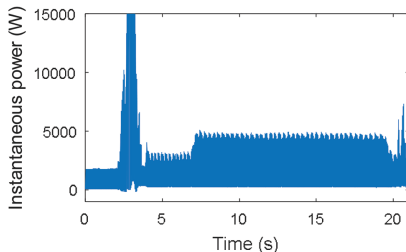

(b) Instantaneous power of $8 \mathrm{~mm}$ cutter at $100 \mathrm{~min}$

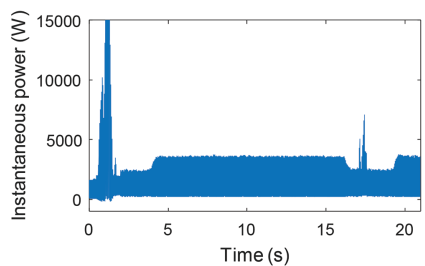

(c) Instantaneous power of $10 \mathrm{~mm}$ cutter at $0 \mathrm{~min}$

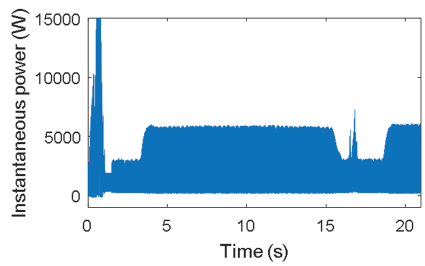

(d) Instantaneous power of $10 \mathrm{~mm}$ cutter at $100 \mathrm{~min}$

Figure 2. Instantaneous power of two cutters at intact and fully worn conditions.

Table 3. Average and max instantaneous power.

\begin{tabular}{lll}
\hline & $\begin{array}{l}\text { Average } \\
\text { power } \\
\text { (W) }\end{array}$ & $\begin{array}{l}\text { Max } \\
\text { power } \\
\text { (W) }\end{array}$ \\
\hline $8 \mathrm{~mm}$ tool at $0 \mathrm{~min}$ & 1593.7 & 3277.4 \\
$8 \mathrm{~mm}$ tool at $100 \mathrm{~min}$ & 1989.6 & 4890.1 \\
$10 \mathrm{~mm}$ tool at $0 \mathrm{~min}$ & 1712.3 & 3827.7 \\
$10 \mathrm{~mm}$ tool at $100 \mathrm{~min}$ & 2537.5 & 5971.5 \\
\hline
\end{tabular}

function is used in the WPT analysis, which can be written as follows:

$$
\Psi_{j, k}(t)=\sqrt{j} \operatorname{sinc}(j t) e^{2 \pi i k t}
$$

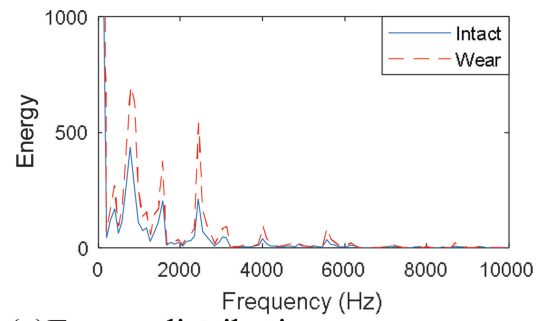

(a)Energy distribution

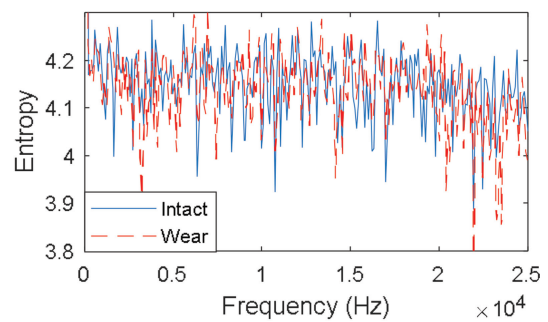

(b) Entropy distribution

Figure 3. Energy and Entropy distributions of $8 \mathrm{~mm}$ cutter at intact and worn conditions.

Energy and entropy are then calculated from each reconstructed signal. Figure 3 depicts the distribution of energy and entropy over the whole frequency range. It should be noted that as the distributions are similar for the two end milling tools, only energy and entropy distribution from the $8 \mathrm{~mm}$ tool are illustrated herein.

It can be seen from Figure 3 that the energy distribution shows similar trends for both intact and worn conditions, and the maximum energy is concentrated at around $700 \mathrm{~Hz}$. However, the entropy distributes well along the whole frequency range, and the entropy distribution at intact and worn conditions shows clear variation. This indicates that the energy features can provide more consistent results, while entropy features are more sensitive to the change in the cutting parameters.

In this study, the two highest energies and entropies at the intact condition are selected for the discrimination, as they represent the most information and disorganization in the original signal. Figure 4 depicts the discrimination results. It should be noted that each point in Figure 4 represent the feature calculated with a two-second length instantaneous power signal.

From Figure 4, it can be seen that with selected energy and entropy features, all four different states, i.e. two end milling tools with two wear levels, can be discriminated with good quality, indicating that not only the worn condition can be identified clearly for the same cutting tool, but the different cutting tools with similar worn levels can also be separated accurately. 


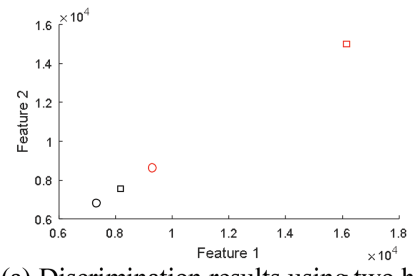

(a) Discrimination results using two highest energies

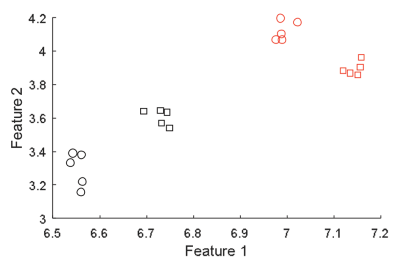

(b) Discrimination results using two highest entropies

Figure 4. Discrimination results using two highest energies and entropies.

When this approach is used in practical applications, the state of the end milling tool can be determined with the minimum Euclidean distance between features (two highest energies or entropies) of instantaneous power from the unknown state and the features shown in Figure 4. It should be mentioned that as the analysis is computational efficient (only taking about 20 seconds to gain the results), this approach can be used in the practical application for on-line monitoring purposes.

\subsection{Discrimination of different cutting tools with different wear level and similar instantaneous power}

The performance of WPT in discriminating cutting tool conditions is further investigated using the data from the end milling tools at different cutting parameters but having similar instantaneous power, which makes it extremely difficult for discrimination using time-domain techniques.

In this study, two sets of data are used for the analysis, including end milling tools with diameters of $6 \mathrm{~mm}$ and $10 \mathrm{~mm}$ at different wear levels and cutting parameters. Table 4 lists the cutting parameters of these two end mill tools and the corresponding wear measurements.

Figure 5 depicts the instantaneous powers from these two end milling tools. Similar instantaneous power can be observed due to the combination of different wear levels and cutting parameters. The average instantaneous powers from these conditions are listed in Table 5. It can be seen that these two conditions will provide similar average instantaneous power, while clear
Table 4. Cutting parameters and corresponding wear measurements.

\begin{tabular}{cllll}
\hline $\begin{array}{l}\text { Dia. } \\
(\mathrm{mm})\end{array}$ & $\begin{array}{l}\text { Spindle } \\
\text { speed } \\
(\mathrm{RPM})\end{array}$ & $\begin{array}{l}\text { Feed } \\
\text { rate } \\
(\mathrm{m} / \mathrm{min})\end{array}$ & $\begin{array}{l}\text { Time } \\
(\mathrm{min})\end{array}$ & $\begin{array}{l}\text { Wear } \\
\text { measurement } \\
(\mathrm{mm})\end{array}$ \\
\hline 8 & 4000 & 580 & 60 & 0.279 \\
10 & 3100 & 600 & 0 & 0 \\
\hline
\end{tabular}

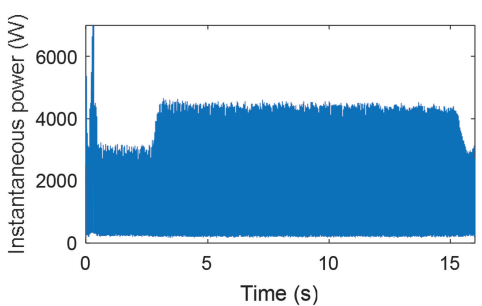

(a)Instantaneous power from $8 \mathrm{~mm}$ cutter

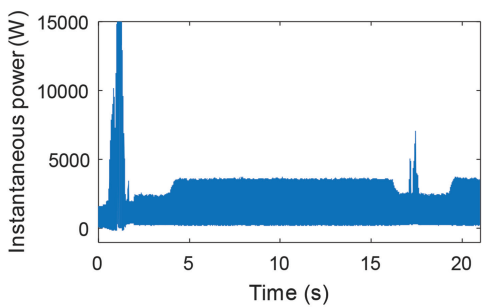

(b) Instantaneous power from $10 \mathrm{~mm}$ cutter

Figure 5. Instantaneous powers from $6 \mathrm{~mm}$ and $10 \mathrm{~mm}$ diameter end mill tools.

Table 5. Average and max instantaneous power.

\begin{tabular}{lll}
\hline & $\begin{array}{l}\text { Average } \\
\text { power } \\
(\mathrm{W})\end{array}$ & $\begin{array}{l}\text { Max } \\
\text { power } \\
(\mathrm{W})\end{array}$ \\
\hline $8 \mathrm{~mm}$ tool at $60 \mathrm{~min}$ & 1810.1 & 4461.2 \\
$10 \mathrm{~mm}$ tool at $0 \mathrm{~min}$ & 1712.3 & 3827.7 \\
\hline
\end{tabular}

variation is observed in the wear level, which is listed in Table 4.

WPT described in section 2 is applied to extract the wavelet coefficients over 8 levels, and signals at different frequency sub-bands are reconstructed. The two highest energies and entropies are then selected for the discrimination. Results are depicted in Figure 6.

It can be seen from Figure 6 that with the selected energy and entropy, the two end milling tools can be discriminated with good quality, indicating the effectiveness of the proposed approach in identifying the states of different end mill tools at varying cutting parameters. 


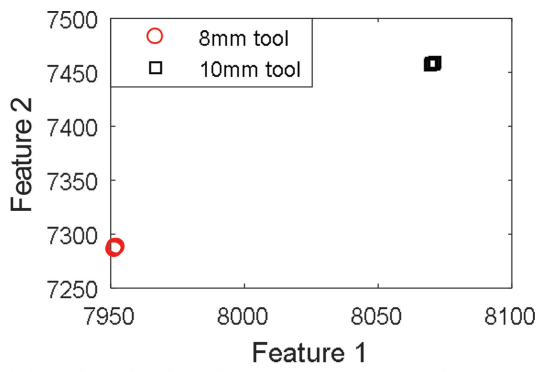

(a) Discrimination using energies

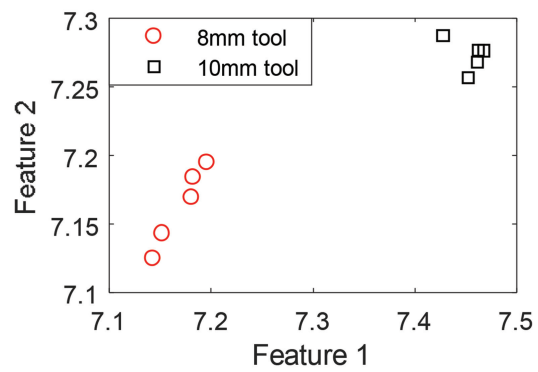

(b) Discrimination using entropies

Figure 6. Discrimination results of $6 \mathrm{~mm}$ and $10 \mathrm{~mm}$ tools at different conditions.

\section{CONCLUSIONS}

In this paper, the discrimination of end mill tools with different diameters, wear levels, and cutting parameters is investigated. Wavelet packet transform is applied to extract wavelet coefficients from the original signal. Signals at different frequency sub-bands are then reconstructed using wavelet coefficients from which energy and entropy are calculated. The two highest energies and entropies are selected to discriminate different cutting tool states.

Two cases are used in this study to investigate the performance of the proposed method; cutting tools with different diameters and wear levels, and cutting tools with different diameters and wear level but similar instantaneous powers. Results demonstrate that with the proposed approach, the state of the cutting tool can be discriminated with good quality, both the tool wear level and cutting parameters can be discriminated.

Whilst these initial results are promising further work is required to expand the analysis over a wider range of cutting parameters to establish if the methodology holds. Additionally, refinement of the sensor measurement and tool monitoring service is required. At present signal analysis is performed off-line, whilst data is captured at higher frequency $(50 \mathrm{khz})$ increasing the cost of equipment and time of analysis. Optimization of this methodology is required in order to enable on-line monitoring.

\section{ACKNOWLEDGEMENT}

The work is supported by grant EP/K014137/1 for Loughborough University from the UK Engineering and Physical Sciences Research Council (EPSRC). The authors also acknowledge the industrial and academic collaborators of the AI2M project (Adaptive Informatics for Intelligent Manufacturing).

\section{REFERENCES}

Altintas, Y., Yellowley, A. 1989. In-process detection of tool failure in milling using cutting force models. Journal of Engineering for Industry 111(2): 149-157.

Bhaskaran, J., Murugan, M., Balashanmugam, N., Chellamalai, M. 2012. Monitoring of hard turning using acoustic emission signal, Journal of Mechanical Science and Technology 26(2): 609-615

Bhattacharyya, P., Sengupta, D. 2009. Estimation of tool wear based on adaptive sensor fusion of force and power in face milling. International Journal of Production Research 47(3): 817-833.

Byrne, G. 1987. Thermoelectric signal characteristics and average interfacial temperatures in the machining of metals under geometrically defined conditions. International Journal of Machine Tools and Manufacture 27(2): 215-224.

Choi, Y., Narayanaswami, R., Chandra, A. Tool wear monitoring in ramp cuts in end milling using the wavelet transform. International Journal of Advanced Manufacturing Technology 23(5-6): 419-428.

Davoodi, B., Hosseinzadeh, H. 2012. A new method for heat measurement during high speed machining. Measurement 45(8): 2135-2140.

Deng, W.J., Li, Q., Li, B.L., He, Y.T., Xia, W., Tang, Y. 2013. Study on the cutting force of cylindrical turning with novel restricted contact tools. The International Journal of Advanced Manufacturing Technology 69(5-8): 1625-1638.

Dimla, D.E., Lister, P.M. 2000. On-line metal cutting tool condition monitoring I: force and vibration analyses. International Journal of Machine Tools and Manufacture 40(5): 739-768.

Hase, A., Wada, M., Koga, T., Mishina, H. 2013. The relationship between acoustic emission signals and cutting phenomena in turning process. The International Journal of Advanced Manufacturing Technology 70(5-8): 947-955.

He, Y.V., Leung, L.C., Linn, R. 2017. Pareto fronts of machining parameters for trade-off among energy consumption, cutting force and processing time. International Journal of Production Economics 185: $113-127$.

Huang, L., Kemao, Q., Pan, B., Asundi, A.K. 2010. Comparison of Fourier transform, windowed Fourier transform, and wavelet transform methods for phase 
extraction form a signal fringe pattern in fringe projection profilometry. Optics and Lasers in Engineering 48(2): 141-148.

Karimi, N.Z., Heidary, H., Minak, G., Ahmadi, M. 2013. Effect of the drilling process on the compression behavior of glass/epoxy laminates. Composite Structures 98: 59-68.

Kono, D., Matsubara, A., Yamaji, I., Fujita, T. 2008. High-precision machining by measurement and compensation of motion error. International Journal of Machine Tools and Manufacture 48(10): 1103-1110.

Kuljanic, E., Totis, G., Sortino, M. 2009. Development of an intelligent multi-sensor chatter detection system in milling. Mechanical Systems and Signal Processing 23(5): 1704-1718.

Lamraoui, M., Thomas, M., Badaoui, M.El. 2014. Cyclostationarity approach for monitoring chatter and tool wear in high speed milling. Mechanical Systems and Signal Processing 44(1): 177-198.

Lauro, C.H., Brandao, L.C., Baldo, D., Reis, R.A., Davim, J.P. 2014. Monitoring and processing signal applied in machining processes-A review. Measurement 58: 73-86.

Lee, K.J., Lee, T.M., Yang, M.Y. 2006. Tool wear monitoring system for CNC end milling using a hybrid approach to cutting force regulation. International Journal of Machine Tools and Manufacture 48(3-4): 371-379.

Li, X., Djordjevich, A., Venuvinod, P.K. 2000. Currentsensor-based feed cutting force intelligent estimation and tool wear condition monitoring. IEEE Transactions on Industrial Electronics 47(3): 697-702.

Li, X., Quyang, G., Liang, Z. 2008. Complexity measure of motor current signals for tool flute breakage detection in end milling. International Journal of Machine Tools and Manufacture 48(3-4): 371-379.

Li, H.Z., Zeng, H., Chen, X.Q. 2006. An experimental study of tool wear and cutting force variation in the end milling of Inconel 718 with coated carbide inserts. Journal of Materials Processing Technology 180(1-3): 296-304.

Liao, T.W., Ting, C.F., Qu, J., Blau, P.J. 2007. A wavelet-based methodology for grinding wheel condition monitoring. International Journal of Machine Tools and Manufacture 47(3-4): 580-592.

Nouri, M., Fussell, B.K., Ziniti, B.L., Linder, E. 2015 Real-time tool wear monitoring in milling using a cutting condition independent method, International Journal of Machine Tools and Manufacture 89: 1-13.

Prickett, P.W., Johns, C. 1999. An overview of approaches to end milling tool monitoring. International Journal of Machine Tools and Manufacture 39(1): 105-122.

Scheffer, C., Heyns, P.S. 2001. Wear monitoring in turning operations using vibration and strain measurements. Mechanical Systems and Signal Processing 15(6): 1185-1202.

Shao, H., Wang, H.L., Zhao, X.M. 2004. A cutting power model for tool wear monitoring in milling. International Journal of Machine Tools and Manufacture 44(14): 1503-1509.

Simoneau, A., Meehan, J. 2013. The impact of machining parameters on peak power and energy consumption in CNC end milling. Energy and Power 3(5): 85-90.

Teti, R., Jemielniak, K., Donnell, G.O., Dornfeld, D. 2010. Advanced monitoring of machining operations. CIRP Ann. - Manuf. Technol. 59(2): 717-739.

Torrence, C., Compo, G.P. 1995. A wavelet packet approach to transient signal classification. Applied and Computational Harmonic Analysis, 2: 265-278.

Yesilyurt, I., Ozturk, H. 2007. Tool condition monitoring in milling using vibration analysis. International Journal of Production Research 45(4): 1013-1028.

Zhang, J.Z., Chen, J.C. 2007. Tool condition monitoring in an end-milling operation based on the vibration signal collected through a microcontroller-based data acquisition system. The International Journal of Advanced Manufacturing Technology 39(1-2): 118-128.

Zhong, W., Zhao, D., Wang, X. A comparative study on dry milling and little quantity lubricant milling based on vibration signals. International Journal of Machine Tools and Manufacture 50(12): 1057-1064.

Zhu, K., Wong, Y.S., Hong, G.S. 2009. Wavelet analysis of sensor signals for tool condition monitoring: a review and some new results. International Journal of Machine Tools and Manufacture 49(7-8): 537-553. 